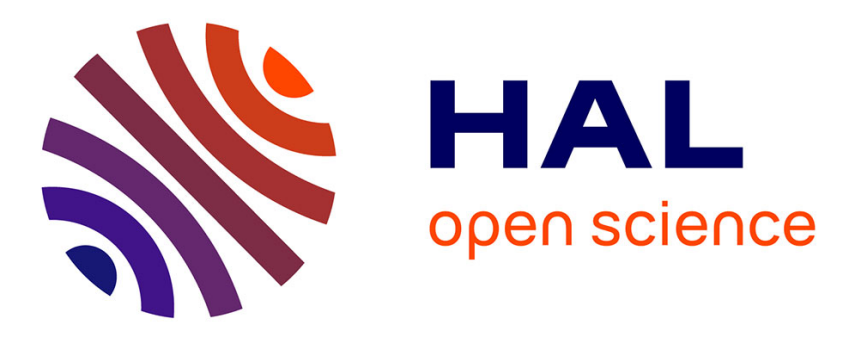

\title{
Facile functionalization of a fully fluorescent perfluorophenyl BODIPY: photostable thiol and amine conjugates
}

Guillaume Vives, Carlo Giansante, Robin Bofinger, Guillaume Raffy, André del Guerzo, Brice Kauffmann, Pinar Batat, Gediminas Jonusauskas, Nathan

D. Mcclenaghan

\section{To cite this version:}

Guillaume Vives, Carlo Giansante, Robin Bofinger, Guillaume Raffy, André del Guerzo, et al.. Facile functionalization of a fully fluorescent perfluorophenyl BODIPY: photostable thiol and amine conjugates. Chemical Communications, 2011, 47 (37), pp.10425-10427. 10.1039/c1cc13778f . hal00628217

\section{HAL Id: hal-00628217 \\ https://hal.science/hal-00628217}

Submitted on 4 Oct 2012

HAL is a multi-disciplinary open access archive for the deposit and dissemination of scientific research documents, whether they are published or not. The documents may come from teaching and research institutions in France or abroad, or from public or private research centers.
L'archive ouverte pluridisciplinaire HAL, est destinée au dépôt et à la diffusion de documents scientifiques de niveau recherche, publiés ou non, émanant des établissements d'enseignement et de recherche français ou étrangers, des laboratoires publics ou privés. 


\title{
Facile functionalization of a fully fluorescent perfluorophenyl BODIPY: photostable thiol and amine conjugates $\dagger$
}

\author{
Guillaume Vives, ${ }^{a}$ Carlo Giansante, ${ }^{a}$ Robin Bofinger, ${ }^{a}$ Guillaume Raffy, ${ }^{a}$ André Del Guerzo, ${ }^{* a}$ \\ Brice Kauffmann, ${ }^{b}$ Pinar Batat, ${ }^{a c}$ Gediminas Jonusauskas ${ }^{c}$ and Nathan D. McClenaghan*a
}

Received 24th June 2011, Accepted 7th August 2011

DOI: $10.1039 / \mathrm{clcc13778f}$

Selective nucleophilic substitution on a perfluorophenyl unit comprising a BODIPY fluorophore using an alkanethiol or a primary amine offers a quantitative fluorophore labelling strategy, while retaining high photostability and emission quantum yields approaching unity.

Photostable fluorescent dyes and labels are widely used in imaging and various microscopies, different types of families being suited to specific excitation wavelengths. Among these fluorophores, dipyrrometheneboron difluoride dyes (commonly referred to as BODIPY) have emerged as a popular choice of fluorophore for different applications including implementation in biological media due to high absorption cross-section, intense emission, as well as specific membrane incorporation. ${ }^{1}$ While a large range of chromophores exhibiting different photophysical properties are known, the number of strategies for ad hoc introduction of fluorescent labels on substrates is rather limited. ${ }^{2}$ Herein we report the use of the specific chemistry of perfluorinated rings to allow efficient labelling of versatile fluorescent synthon $\mathbf{1}$ (Scheme 1) with biologically relevant functional groups, in both organic solvents and aqueous mixtures, whilst typically retaining a quantum yield approaching unity, thus allowing studies down to the single molecule level. It is noteworthy that the methyl groups on the pyrrole rings provide an orthogonal reaction site, ${ }^{3}$ as demonstrated in a structurally related fluorous intermediate which should extend the scope of such synthons in NIR emitter tag development. Indeed a range of chemical reactions for colour tuning BODIPYs have been reported which are a priori compatible with the current synthon. Harnessing the current functionalisation approach with orthogonal reactions holds promise for applications in materials development, e.g. fluorescent focal points in dendrimer synthesis.

\footnotetext{
${ }^{a}$ Univ. Bordeaux, ISM, CNRS UMR 5255, F-33400 Talence, France. E-mail:n.mc-clenaghan@ism.u-bordeaux1.fr,

a.del-guerzo@ism.u-bordeaux1.fr

${ }^{b}$ Univ. Bordeaux, IECB, CNRS UMS 3033, F-33607 Pessac, France

${ }^{c}$ Univ. Bordeaux, LOMA, CNRS UMR 5798, F-33400 Talence,

France

$\dagger$ Electronic supplementary information (ESI) available: Synthetic procedures, HPLC traces for coupling reactions, steady-state absorption and emission spectra, Strickler-Berg treatment, time-resolved emission and transient absorption spectra, photodegradation experiments and confocal fluorescence microscopy setup. See DOI: 10.1039/ c1cc13778f
}

Perfluorinated BODIPY 1 was obtained in a straightforward three step, one-pot reaction (see ESI $\dagger$ for detailed procedure). Commercial perfluorobenzaldehyde was first reacted with 2,4-dimethylpyrrole to afford a dipyrromethane intermediate which was oxidized by $p$-chloranil to a dipyrromethene intermediate. This was then reacted with $\mathrm{BF}_{3}$ to yield $\mathbf{1}$ in $33 \%$ overall yield via a standard procedure. ${ }^{1 a, c, 4}$ Single crystals suitable for X-ray diffraction were obtained from chloroform (recently reported in acetonitrile). ${ }^{3 a}$ The crystallographic structure shows the planar BODIPY moiety and the outof-plane perfluorinated phenyl substituent. Importantly for high fluorescence, the phenyl ring plane presents a $90.0^{\circ}$ angle to the BODIPY plane in the solid state due to steric hindrance induced partly by the methyl groups. On comparing with a related hydrocarbon analogue, the fluorine atoms can also be seen to be responsible for this behaviour. For example replacing the pentafluorophenyl ring with a para-bromophenyl, such that ortho protons replace fluorines resulted in a decreased angle of $78.9^{\circ}$ between planes; while that comprising a dimethylamino group was $87.6^{\circ} .^{5}$

Perfluorinated rings are known to be susceptible to nucleophilic substitution reactions, offering an effective reaction pathway to $\mathrm{C}-\mathrm{C}, \mathrm{C}-\mathrm{S}$ and $\mathrm{C}-\mathrm{N}$ bond formation. ${ }^{6}$ This would thus offer a high-yielding straightforward alternative to metal-catalysed $\mathrm{S}_{\mathrm{N}} 2$ reactions on the BODIPY meso-phenyl ring. ${ }^{7}$ While the Lewis acid boron centre is susceptible to such an attack from aryl Grignards, acetylide anions or alkoxides, ${ }^{1 a, 8}$ it was anticipated to be so less than the electron poor aromatic. Thus under appropriately mild conditions selective F-displacement reactions on the ring could be effected. Nucleophilic aromatic substitution reactions on the perfluorinated ring were tested with substrate 1 using thiol and amine compounds, as represented in Scheme 1. 1 reacted smoothly at room temperature with
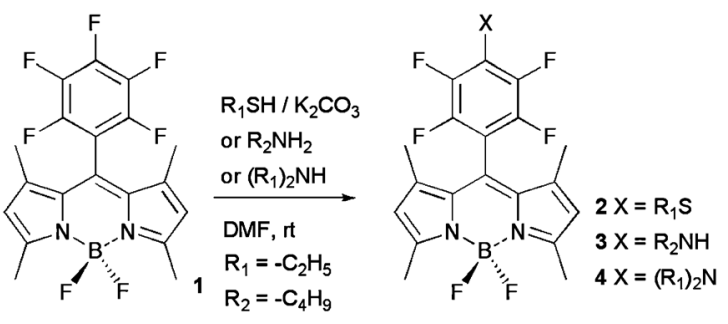

Scheme 1 Synthesis of 2-4 with quantitative conversion for $\mathbf{2}$ and $\mathbf{3}$. 
ethanethiol in the presence of $\mathrm{K}_{2} \mathrm{CO}_{3}$, HPLC analysis showing full disappearance of $\mathbf{1}$ after 40 minutes concomitant with the appearance of a new band with a longer retention time $(6.3 \mathrm{cf}$. 7.7 min, eluting with $96: 4$, cyclohexane/ethyl acetate, v/v). ${ }^{19}$ F-NMR analysis of the crude product showed a clean substitution of the fluorine in the 4-position giving $\mathbf{2}$, as denoted by resonances of the aromatic fluorine atoms at -134.1 and $-143.6 \mathrm{ppm}$ compared with those of 1 at $-161.9,-153.0$ and $-143.5 \mathrm{ppm}$ (see ESI $\dagger$ ), while the quadruplet associated with boron-bound fluorines remained similar at $-146.7 \mathrm{ppm}$ in both compounds.

Reaction with a primary amine was carried out in DMF at room temperature using an 8-fold excess of butylamine. Only one new HPLC signal for substitution product $\mathbf{3}$ could be observed as the starting material was consumed, with ${ }^{19} \mathrm{~F}-\mathrm{NMR}$ resonances of the aromatic fluorines at -147.6 and $-161.6 \mathrm{ppm}$ confirming that substitution in the 4-position had occurred. Secondary amine diethylamine did not react with $\mathbf{1}$ at room temperature despite using a large excess ( 40 eq.) of amine. 4 could be obtained on heating the reaction mixture to $120^{\circ} \mathrm{C}$, however the formation of side products was also observed.

Concerning relative reactivities, Fig. 1 shows the progression of the reaction of $\mathbf{1}$ with primary and secondary amines and thiols, as judged by integrated peak areas in the HPLC trace. The reaction with the thiol was found to be much more rapid, in the presence of base, than the analogous reaction with a primary amine. Simultaneously introducing thiol (5 eq.) and primary amine (8 eq.) to a solution of $\mathbf{1}(24 \mathrm{mM})$ resulted in the quasi-exclusive formation of $\mathbf{2}$. Indeed, integrated peak areas corresponding to products $\mathbf{2}$ and $\mathbf{3}$ showed circa $99 \%$ conversion to $\mathbf{2}$ after only 5 minutes. Thus the selectivity and high reactivity for thiols with the perfluorophenyl moiety under mild conditions is clearly demonstrated. In the absence of base the reaction of $\mathbf{1}$ with ethanethiol is much more sluggish, with only $54 \%$ conversion after 5 days. Importantly, in an aqueous DMF mixture $(1: 1, \mathrm{v} / \mathrm{v})$ the thiol reaction proved equally efficient and a similar selectivity toward thiol $v s$. amine conjugate formation was obtained (see ESI $\dagger$ ). Indeed in this protic environment the amine proved unreactive under these mild conditions.

Parent BODIPY $\mathbf{1}$ and derivatives $\mathbf{2}, \mathbf{3}$ and $\mathbf{4}$ showed strong absorption and intense emission, with a small Stokes shift as shown by data regrouped in Table 1 (see spectra in Fig. S12-S15 (ESI $\dagger))$. Molar extinction coefficients for the lowest energy visible absorption band are similarly high in all cases,

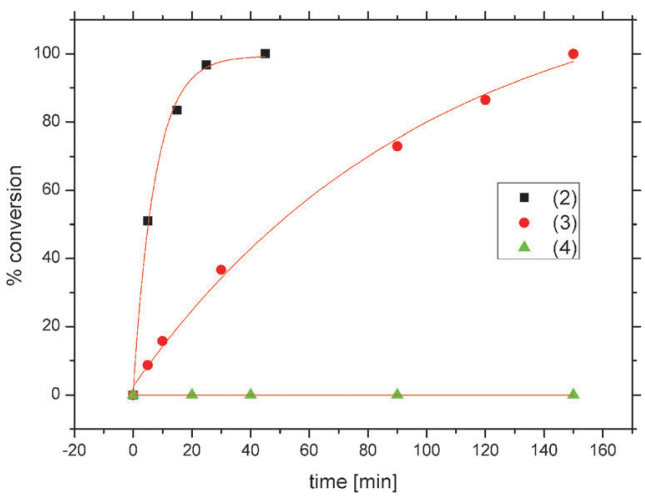

Fig. 1 Progression of nucleophilic substitution reaction of 1 with different substrates at room temperature, based on HPLC analysis.
Table 1 Spectroscopic data for 1-4 in air-equilibrated THF

\begin{tabular}{lllllll}
\hline Sample & $\lambda_{\text {max }} / \mathrm{nm}$ & $\varepsilon / \mathrm{M}^{-1} \mathrm{~cm}^{-1}$ & $\lambda_{\mathrm{em}} / \mathrm{nm}$ & $\Phi_{f}$ & $\tau_{\text {calc }} / \mathrm{ns}$ & $\tau / \mathrm{ns}$ \\
\hline $\mathbf{1}$ & 516 & 78600 & 527 & 0.98 & 5.8 & 6.1 \\
$\mathbf{2}$ & 516 & 77000 & 527 & 0.90 & 5.4 & 5.9 \\
$\mathbf{3}$ & 514 & 78700 & 525 & 0.93 & 6.1 & 5.7 \\
$\mathbf{4}$ & 515 & 77200 & 523 & 0.96 & 6.0 & 5.7 \\
\hline
\end{tabular}

and the maximum absorption wavelength is almost unchanging, being almost coincident with popular argon ion laser, which emits at $514 \mathrm{~nm}$, and shows that remote substitution has a negligible effect on absorption properties. Relatively few fluorophores are perfectly adapted for this wavelength, one example being expensive sulfonated rhodamine derivatives (Alexa Fluor $514^{\mathbb{R}}$ ). Importantly, the quantum yield which is essentially unity for parent 1 remains high $(\geq 90 \%)$ in all cases although the substituted species are slightly lower than the parent. ${ }^{9}$ The strongly allowed nature of the $\mathrm{S}_{1} \leftarrow \mathrm{S}_{0}$ transition, as denoted by the strong molar extinction coefficients allows estimation of the excited-state lifetime using a Strickler-Berg analysis (see ESI $\dagger$ ). ${ }^{10}$ Estimated fluorescence lifetimes $\left(\tau_{\text {calc }}\right.$, Table 1$)$ on the nanosecond scale are in good agreement with the measured values. This suggests that the excited parent and derivatives are all structurally reminiscent to that of the respective ground-state species and that solvent interactions are unchanging.

It is noteworthy that similarly high quantum yield values were obtained for $\mathbf{1}$ and $\mathbf{2}$ in an $\mathrm{H}_{2} \mathrm{O}$ : DMF mixture $(75: 25, \mathrm{v} / \mathrm{v})$ at $91 \%(\tau=6.6 \mathrm{~ns})$ and $93 \%(\tau=6.6 \mathrm{~ns})$, respectively. Meanwhile the amine-conjugate 3 exhibited a drastically reduced value at $1 \%$, presumably partly due to hydrogenbonding enhanced vibrational quenching. The photostability of molecules 1-3 was evaluated on irradiation in air-equilibrated solution. The quantum yields for photodegradation $\left(\Phi_{\text {bleach }}\right)$ were estimated to be $2.7 \times 10^{-5}, 4.1 \times 10^{-5}$ and $2.7 \times 10^{-5}$, respectively, somewhat lower than the $7.5 \times 10^{-5}$ measured for fluorescein isocyanate (which is on the same order of magnitude as a literature value in deoxygenated EtOH). ${ }^{11}$

Picosecond transient absorption (Fig. S16, ESI $\dagger$ ) spectroscopy was employed to follow the evolution of excited 1, a representative member of the series, and notably to elucidate the presence of any dark-states which may have been introduced, could not be detected by fluorescence, and would represent an unwanted alternative non-emissive deexcitation/ degradation pathway. A qualitatively similar excited-state absorption spectrum to that of a multicomponent BODIPY containing supermolecule, with positive absorption features at $350 \mathrm{~nm}$ and $420 \mathrm{~nm}$ and a band close to the ground state absorption wavelength allows us to conclude that no significant population of states other than the emissive $S_{1}$ state occurs. ${ }^{12}$

High quantum yield, no apparent population of dark states and relatively high photostability for $\mathbf{1}$ make this label potentially suitable as a single molecule emitter. $\mathbf{1}$ was dispersed into a PMMA matrix and evaluated using confocal fluorescence microscopy under deoxygenated conditions (for more details, see ref. 13 and $\mathrm{ESI} \dagger$ ). In preliminary studies, a linearly polarized laser excitation at a standard wavelength of $488 \mathrm{~nm}$ with a power of $1.5 \mathrm{~kW} \mathrm{~cm}{ }^{-2}$ was used. ${ }^{14}$ Emission trajectories on single molecules show the typical blinking of the fluorescence (Fig. 2a), due to the reversible conversion between singlet $\mathrm{ON}$ states and 

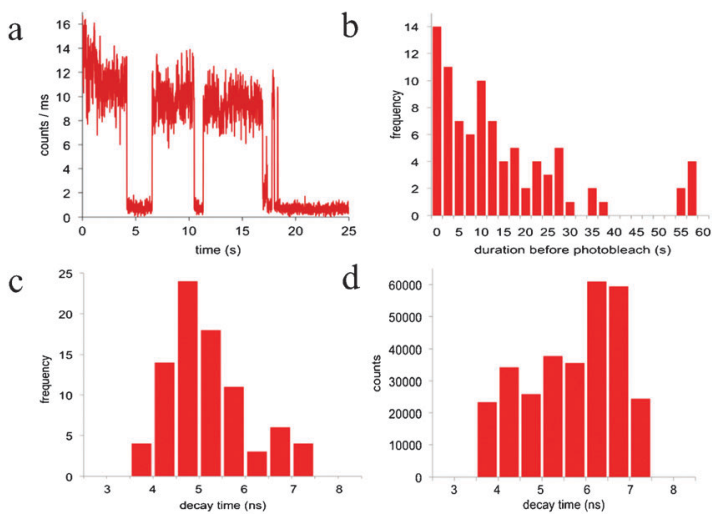

Fig. 2 Single molecule emission of 1 in PMMA $\left(\lambda_{\mathrm{ex}}=488 \mathrm{~nm}, \lambda_{\mathrm{em}}>\right.$ $500 \mathrm{~nm}$ ): (a) emission trajectory of a single molecule (number of photons detected per ms); (b-c) distribution for 82 single molecules of: the total duration of emission before photobleaching (b); the decay time (c); correlation between the decay time and the average number of counts emitted before photobleaching (d).

OFF states. For $50 \%$ of 82 molecules of 1 the peak emission intensity reflecting the brightness reached at least $5.3 \times 10^{3}$ photons s ${ }^{-1}$ detected, and up to $2.9 \times 10^{4}$ photons s $^{-1}$. These values are in agreement with a maximum theoretical upper limit of $2.9 \times 10^{5}$ photons $\mathrm{s}^{-1}$ emitted, ${ }^{15,16}$ but lower due to losses resulting from the random orientation of the molecules relative to the excitation beam polarization and the instrumental detection efficiency. From $50 \%$ of the molecules, we have detected at least $2.1 \times 10^{4}$ photons and in the best case up to $2.4 \times 10^{5}$ photons before photobleaching (Fig. S19 in ESI $\dagger$ ). Considering the same limitations as above, this reflects the measured $1 / \Phi_{\text {bleach }}=3.7 \times 10^{4}$ photons in solution and is in agreement with known organic emitters. ${ }^{16}$ This emission occurs within 11 seconds for $50 \%$ of the molecules and the duration can reach 1 minute (Fig. 2b). The distribution of decay times of $\mathbf{1}$ is represented in the bar chart in Fig. 2c, peaking around $4.9 \mathrm{~ns}$ and displaying some longer values around $6.8 \mathrm{~ns}$. The average decay time is $5.1 \mathrm{~ns}$, with a standard deviation of $0.9 \mathrm{~ns}$, and is thus only slightly shorter than in THF solutions. This could result from an enhanced non-radiative deactivation of the excited states in the polymer environment.

Interestingly, a small population of molecules shows longer decay times and emits a higher average total amount of photons (Fig. 2d). In a previous study of single molecules in PMMA, ${ }^{17}$ two populations of emitters were also observed and the minor one was attributed to molecules embedded in the more rigid micro-environments of PMMA. 1 shows thus some sensitivity to the environment while preserving suitable emissive properties.

In conclusion, perfluorophenyl rings can be readily and selectively functionalised through $\mathrm{C}-\mathrm{N}$ and $\mathrm{C}-\mathrm{S}$ bond formation, for example in a BODIPY chromophore derivative. These conjugates are extremely photostable with high absorption and emission in an organic solvent. In aqueous mixtures, high selectivity for thiol $v s$. amine ( $\geq 100$-fold) conjugate formation conspires with the 90-fold higher quantum yield to make the thiol conjugate label particularly attractive. Applications in labelling and staining are thus envisaged, which can in principle similarly be applied to other fluorophores encompassing the perfluorophenyl motif.
Financial support from the European Research Council under the European Community's Seventh Framework Programme (FP7/2008-2013) ERC grant agreement no. 208702; Région Aquitaine; Ministère de la Recherche et de l'Enseignement Supérieur (P.B) is gratefully acknowledged.

\section{Notes and references}

1 (a) A. Loudet and K. Burgess, Chem. Rev., 2007, 107, 4891; (b) A. C. Benniston and G. Copley, Phys. Chem. Chem. Phys., 2009, 11, 4124; (c) R. Ziessel, G. Ulrich and A. Harriman, New J. Chem., 2007, 31, 496; (d) C. Nicoli, J. Baranski, S. Schlummer, J. Palomo, M. Lumbierres-Burgues, M. Kahms, J. Kuhlmann, S. Sanchez, E. Gratton, H. Waldmann and R. Winter, J. Am. Chem. Soc., 2006, 128, 192; (e) F. Bestvater, E. Spiess, G. Strobrawa, M. Hacker, T. Feurer, T. Porwol, U. BerchnerPfannschmidt, C. Wostlaw and H. Acker, J. Microsc., 2002, 208, 108; $(f)$ C. Trieflinger, K. Rurack and J. Daub, Angew. Chem., Int. Ed., 2005, 44, 2288; ( $g$ ) F. Bergström, I. Mikhalyov, P. Hägglöf, R. Wortmann, T. Ny and L. B.-Å. Johansson, J. Am. Chem. Soc., 2002, 124, 196.

2 For examples of BODIPY-protein conjugates, see: (a) J. Lee, S. Lee, D. Zhai, Y. Ahn, H. Yun Yeo, Y. Ling and T. Chang, Chem. Commun., 2011, 47, 4508; (b) S. Niu, C. Massif, G. Ulrich, R. Ziessel, P. Renard and A. Romieu, Org. Biomol. Chem., 2011, 9, 66; (c) D. Wang, J. Fan, X. Gao, B. Wang, S. Sun and X. Peng, J. Org. Chem., 2009, 74, 7675; (d) M. Isaksson, P. Hägglöf, P. Håkansson, T. Ny and L. Johansson, Phys. Chem. Chem. Phys., $2007,9,3914$.

3 (a) X. F. Zhou, Acta Crystallogr., Sect. E, 2010, 66, o757N; (b) O. Galangau, C. Dumas-Verdes, R. Méallet-Renault and G. Clavier, Org. Biomol. Chem., 2010, 8, 4546.

4 (a) N. Basaríc, M. Baruah, W. Qin, B. Metten, M. Smet, W. Dehaen and N. Boens, Org. Biomol. Chem., 2005, 3, 2755.

5 (a) D.-C. Wang, C. He, J.-L. Fan, W.-W. Huang and X.-J. Peng, Acta Crystallogr., Sect. E: Struct. Rep. Online, 2007, 63, o2900; (b) Y.-H. Yu, Z. Shen, H.-Y. Xu, Y.-W. Wang, T. Okujima, N. Ono, Y.-Z. Li and X.-Z. You, J. Mol. Struct., 2007, 827, 130.

6 C. R. Becer, R. Hoogenboom and U. S. Schubert, Angew. Chem., Int. Ed., 2009, 48, 4900.

7 V. Leen, F. Schevenels, J. Cui, C. Xu, W. Yang, X. Tang, W. Liu, W. Qin, W. M. De Borggraeve, N. Boens and W. Dehaen, Eur. J. Org. Chem., 2009, 5920.

8 (a) C. Goze, G. Ulrich, L. J. Mallon, B. D. Allen, A. Harriman and R. Ziessel, J. Am. Chem. Soc., 2006, 128, 10231; (b) G. Ulrich, C. Goze, M. Guardigli, A. Roda and R. Ziessel, Angew. Chem., Int Ed., 2005, 44, 3694; (c) C. Tahtaoui, C. Thomas, F. Rohmer, P. Klotz, G. Duportail, Y. Mély, D. Bonnet and M. Hibert, J. Org. Chem., 2007, 72, 269; (d) Y. Gabe, T. Ueno, Y. Urano, H. Kojima and T. Nagano, Anal. Bioanal. Chem., 2006, 386, 621; (e) T. Rohand, M. Baruah, W. Qin, N. Boens and W. Dehaen, Chem. Commun., 2006, 266.

9 Fluorescein standard, $\Phi_{\mathrm{f}}=0.95$ in $0.1 \mathrm{M} \mathrm{NaOH}$ (aq); J. H. Brannon and D. Magde, J. Phys. Chem., 1978, 82, 705.

10 (a) S. J. Strickler and R. A. Berg, J. Chem. Phys., 1962, 37, $814 ;$ (b) J. B. Birks, Photophysics of aromatic molecules, Wiley Interscience, London, Date: 1970.

11 P. Meallier, S. Guittonneau, C. Emmelin and T. Konstantinova, Dyes Pigm., 1999, 40, 95.

12 F. Puntoriero, F. Nastasi, S. Campagna, T. Bura and R. Ziessel, Chem.-Eur. J., 2010, 16, 8832.

13 C. Giansante, G. Raffy, C. Schäfer, H. Rahma, M.-T. Kao, A. G. L. Olive and A. Del Guerzo, J. Am. Chem. Soc., 2011, 133, 316.

14 Although the absorption and emission would be higher at $\lambda_{\mathrm{ex}}=$ 514 or $516 \mathrm{~nm}$, this wavelength was not available on our microscopy setup. $0.1 \mathrm{nM}$ of $\mathbf{1}$ were dissolved in deoxygenated THF with PMMA $\left(10 \mathrm{mg} \mathrm{mL}^{-1}\right)$ and spin-coated on a glass slide. Measurements performed at $22{ }^{\circ} \mathrm{C}$.

15 Assuming the same absorption cross-section and emission quantum yield of 1 in PMMA and in solution.

16 W. E. Moerner and D. P. Fromm, Rev. Sci. Instrum., 2003, 74, 3597.

17 Y. Hou, A. M. Bardo, C. Martinez and D. A. Higgins, J. Phys. Chem. B, 2000, 104, 212. 